\title{
Examination of Necessity for Pelvic Drain Placement After Robot-assisted Radical Prostatectomy
}

\author{
HIROAKI IWAMOTO ${ }^{1}$, YOSHIFUMI KADONO ${ }^{1}$, RYUNOSUKE NAKAGAWA ${ }^{1}$, TOMOYUKI MAKINO ${ }^{2}$, \\ SUGURU KADOMOTO $^{1}$, HIROSHI YAEGASHI ${ }^{1}$, MASASHI IIJIMA ${ }^{1}$, SHOHEI KAWAGUCHI ${ }^{1}$, \\ TAKAHIRO NOHARA ${ }^{1}$, KAZUYOSHI SHIGEHARA $^{1}$, KOUJI IZUMI $^{1}$ and ATSUSHI MIZOKAMI ${ }^{1}$ \\ ${ }^{1}$ Department of Integrative Cancer Therapy and Urology, \\ Kanazawa University Graduate School of Medical Science, Kanazawa, Japan; \\ ${ }^{2}$ Department of Urology, Ishikawa Prefectural Central Hospital, Kanazawa, Japan
}

\begin{abstract}
Background/Aim: Pelvic drain (PD) placement is commonly performed after robot-assisted radical prostatectomy (RARP), but the need for PD placement is unclear. This study aimed to assess the need for PD placement after RARP. Patients and Methods: This retrospective study analysed the effect of $P D$ placement on postoperative complications in patients who underwent RARP between 2009 and 2018. All patients prior to October 1, 2016 had a PD placed; those after did not. Results: Of the 308 study patients, 231 received a PD (PD group) and 77 did not (ND group). The incidence of ileus, urinary tract infection and anastomotic leak did not differ significantly between the groups; nor did the incidence of asymptomatic and symptomatic lymphocele at 2 weeks and 1 year after surgery. Multivariate analysis showed that lymph node dissection is a predictor of asymptomatic lymphocele development two weeks after surgery. Conclusion: PD placement is not necessary after RARP.
\end{abstract}

Prostate cancer is the most common cancer and second leading cause of cancer-related mortality in men (1). Most prostate cancers are diagnosed as localized prostate cancer (2, 3 ). Radical prostatectomy (RP) is the gold standard treatment for clinically localised prostate cancer (4). In addition to open

This article is freely accessible online.

Correspondence to: Yoshifumi Kadono, Department of Integrative Cancer Therapy and Urology, Graduate School of Medical Science, Kanazawa University, Takaramachi13-1, Kanazawa, Ishikawa 9208640, Japan. Tel: +81 762652393, Fax: +81 762344263, e-mail: yskadono@yahoo.co.jp

Key Words: Prostate cancer, pelvic drain, robot-assisted radical prostatectomy, lymphocele, pelvic lymph node dissection. radical prostatectomy (ORP) and laparoscopic radical prostatectomy, robot-assisted RP (RARP) has become widely used in recent years and is often the first choice of treatment $(5,6)$. Pelvic drain (PD) placement is commonly performed after RARP to prevent the formation of urinary cysts, pelvic hematomas and lymphoceles that would require further treatment. RARP has the same oncological outcome as ORP $(7,8)$ and is associated with shorter operation time and length of hospital stay, less bleeding and higher rate of erectile function improvement (8-10). This raises a question regarding the need for routine pelvic drainage after RARP. After experiencing two cases of ileus that may have been due to PD placement, we have not been placing PDs. Here, we present an uncontrolled before-after study that examined outcomes of PD placement, focusing on prevention of lymphoceles and other complications.

\section{Patients and Methods}

We retrospectively reviewed the charts of all patients who underwent transperitoneal RARP at Kanazawa University Hospital between May 2009 and April 2018 to record and analyse relevant data. PDs were routinely placed in all patients prior to October 1, 2016; they were not placed afterward. Preoperative evaluation included digital rectal examination, transrectal ultrasonography, measurement of serum prostate specific antigen (PSA) level and 1012-core systematic prostate biopsies for cancer detection; cancer staging was conducted using computerised tomography (CT), magnetic resonance imaging (MRI) and bone scintigraphy. CT or MRI was performed approximately 2 weeks and 1 year after RARP to evaluate the presence of pelvic fluid retention. The need for and extent of lymph node dissection and use of nerve-sparing technique were at the discretion of the attending surgeon.

The collected medical data included age, body mass index (BMI), serum PSA level, prostate volume (PV), prostate biopsy pathology, clinical stage, imaging findings and surgical details. Pelvic fluid retention was determined using triaxial ellipsoid approximation. Complications were graded according to the extended Clavien-Dindo system: asymptomatic lymphocele was 
Table I. Patient characteristics.

\begin{tabular}{|c|c|c|c|}
\hline Variable & $\mathrm{PD}$ & ND & $p$-Value \\
\hline Number of patients & 231 & 77 & \\
\hline Median age at surgery, years (range) & $66(50-76)$ & $68(57-76)$ & 0.007 \\
\hline Median BMI, $\mathrm{kg} / \mathrm{m}^{2}$ (range) & $23.6(17.4-31.5)$ & $23.5(17.8-29.7)$ & 0.73 \\
\hline Preoperative PSA level, $\mathrm{ng} / \mathrm{ml}$ (range) & $6.8(1.8-90.1)$ & $5.8(2.4-74.2)$ & 0.03 \\
\hline Biopsy GS (\%) & & & 0.81 \\
\hline$\leq 6$ & $75(32.5)$ & $22(28.6)$ & \\
\hline 7 & $104(45)$ & $37(48.1)$ & \\
\hline$\geq 8$ & $52(22.5)$ & $18(23.4)$ & \\
\hline Clinical stage $(\%)$ & & & 1 \\
\hline$\leq \mathrm{T} 2$ & $219(94.8)$ & $73(94.8)$ & \\
\hline$\geq \mathrm{T} 3$ & $12(5.2)$ & $4(5.2)$ & \\
\hline D'Amico risk classification (\%) & & & 0.98 \\
\hline Low & $62(26.8)$ & $21(27.3)$ & \\
\hline Intermediate & $91(39.4)$ & $31(40.3)$ & \\
\hline High & $78(33.8)$ & $25(32.5)$ & \\
\hline History of abdominal surgery $(\%)$ & & & 0.6 \\
\hline+ & $94(40.7)$ & $34(44.2)$ & \\
\hline- & $137(59.3)$ & $43(55.8)$ & \\
\hline Neoadjuvant ADT (\%) & & & 0.12 \\
\hline+ & $46(19.9)$ & $9(11.7)$ & \\
\hline - & $185(80.1)$ & $68(88.3)$ & \\
\hline Median estimate PV, ml (range) & $24.5(3.6-78.9)$ & $24.3(7.3-97)$ & 0.29 \\
\hline
\end{tabular}

PD: Pelvic drain; ND: no pelvic drain; BMI: body mass index; PSA: prostate specific antigen; GS: Gleason score; ADT: androgen deprivation therapy; PV: prostate volume.

classified as grade 1 and symptomatic lymphocele was classified as grade $\geq 3$ (11).

Statistical analyses were performed using SPSS software version 17.0 (IBM Corp., Armonk, NY, USA) and Prism software version 5 (GraphPad Software, San Diego, CA, USA). The chi-square and Mann-Whitney $U$-tests were used to compare data between groups. Binomial logistic regression was used for multivariate analyses. $p<0.05$ was considered significant. The present study was approved by the institutional review board of Kanazawa University Hospital (2016-328).

\section{Results}

RARP was performed in 308 patients during the study period. The PD group was comprised of 231 patients and the no PD (ND) group was comprised of 77. Table I shows the patient characteristics. The median age at the time of surgery was significantly lower in the PD group than in the ND group (66 years and 68 years, respectively; $p=0.007$ ). Furthermore, the median preoperative PSA level was significantly lower in the PD group than in the ND group $(6.8 \mathrm{ng} / \mathrm{ml}$ and $5.8 \mathrm{ng} / \mathrm{ml}$, respectively, $p=0.03)$. There were no significant differences between the two groups in median BMI, biopsy Gleason score (GS), clinical stage, D’Amico risk classification, history of abdominal surgery, proportion of patients receiving neoadjuvant androgen deprivation therapy, or median estimated PV.
Table II shows the perioperative and pathological outcomes of the two groups. The PD group had a significantly higher proportion of patients who underwent pelvic lymph node dissection (PLND) (48.1\% vs. $24.7 \%$, $p<0.001)$ and higher median estimated blood loss $(100 \mathrm{ml}$ vs. $80 \mathrm{ml}, p=0.03)$. The median length of hospital stay was significantly longer in the PD group (6.8 days vs. 5.8 days, $p<0.001)$. There were no significant differences between the two groups in median operation time, pathological GS, pathological stage, median volume of resected prostate, median length of urinary catheter placement period, or proportion of patients who underwent nerve-sparing surgery, received a complete resection, or had extraprostatic extension. The incidence of complications, including ileus, urinary tract infection (UTI) with fever and anastomotic leak, did not significantly differ between the two groups; nor did the incidence of asymptomatic and symptomatic lymphocele at 2 weeks and 1 year after surgery.

Table III shows the results of the univariate and multivariate analyses for predictors of asymptomatic lymphocele 2 weeks after surgery. Significant univariate predictors included BMI $<25 \mathrm{~kg} / \mathrm{m}^{2}$ ( $\left.p=0.04\right)$, biopsy GS $\geq 8$ $(p=0.03)$, pelvic lymph node dissection $(p<0.001)$ and pathological GS $\geq 8(p=0.03)$. In the multivariate analyses, the only significant independent predictor was pelvic lymph node dissection $(p<0.001)$. 
Table II. Perioperative and pathological outcomes.

\begin{tabular}{|c|c|c|c|}
\hline Variable & $\mathrm{PD}$ & ND & $p$-Value \\
\hline Number of patients & 231 & 77 & \\
\hline Median operating time, minute (range) & $234(138-398)$ & $239(177-352)$ & 0.3 \\
\hline Median console time, minute (range) & $180(102-350)$ & $176(123-306)$ & 0.74 \\
\hline Median estimated blood loss, $\mathrm{ml}$ (range) & $100(0-1350)$ & $80(0-510)$ & 0.03 \\
\hline Pathological GS (\%) & & & 0.045 \\
\hline No malignancy & $10(4.3)$ & $1(1.3)$ & \\
\hline$\leq 6$ & $58(25.1)$ & $11(14.3)$ & \\
\hline 7 & $126(54.5)$ & $58(75.3)$ & \\
\hline$\geq 8$ & $17(7.4)$ & $7(9.1)$ & \\
\hline Unknown & $20(8.7)$ & $0(0)$ & \\
\hline Pathological stage (\%) & & & 0.18 \\
\hline$\leq \mathrm{T} 2$ & $191(82.7)$ & $58(75.3)$ & \\
\hline$\geq \mathrm{T} 3$ & $40(17.3)$ & $19(24.7)$ & \\
\hline Pelvic lymph node dissection (\%) & & & $<0.001$ \\
\hline None & $120(51.9)$ & $58(75.3)$ & \\
\hline Limited or extended & $111(48.1)$ & $19(24.7)$ & \\
\hline Nerve sparing (\%) & & & 0.22 \\
\hline None & $42(18.2)$ & $9(11.7)$ & \\
\hline Limited or bilateral & $189(91.8)$ & $68(88.3)$ & \\
\hline Median hospital stay, days (range) & $15(9-48)$ & $12(9-25)$ & $<0.001$ \\
\hline RM & & & 0.062 \\
\hline 0 & $194(84.0)$ & $57(74.0)$ & \\
\hline 1 & $37(16.0)$ & $20(26.0)$ & \\
\hline EPE & & & 0.19 \\
\hline 0 & $199(86.1)$ & $62(80.5)$ & \\
\hline 1 & $29(12.6)$ & $15(19.5)$ & \\
\hline $\mathrm{X}$ & $3(1.3)$ & $0(0)$ & \\
\hline Median removed PV, ml (range) & $37(15-87)$ & $38(18-113)$ & 0.3 \\
\hline Ileus $(\%)$ & $8(3.5)$ & $1(1.3)$ & 0.46 \\
\hline Febrile urinary tract infection $(\%)$ & $3(1.3)$ & $0(0)$ & 0.58 \\
\hline Anastomotic leak (\%) & $10(4.3)$ & $4(5.2)$ & 0.76 \\
\hline Median urinary catheter placement period, day (range) & $7(5-41)$ & $7(6-21)$ & 0.055 \\
\hline Average liquid storage for 2 weeks after surgery, $\mathrm{ml}$ (range) & $8.9(0-229)$ & $10.9(0-210)$ & 0.55 \\
\hline Average liquid storage for 1 year after surgery, $\mathrm{ml}$ (range) & $1.4(0-232)$ & 0 & n.d. \\
\hline Asymptomatic lymphocele for 2 weeks after surgery $(\%)$ & $29(12.6 \%)$ & $12(15.6 \%)$ & 0.56 \\
\hline Asymptomatic lymphocele for 1 year after surgery $(\%)$ & $3(1.3 \%)$ & 0 & n.d. \\
\hline Symptomatic lymphocele $(\%)$ & $1(0.4 \%)$ & 0 & n.d. \\
\hline
\end{tabular}

GS: Gleason score; RM: resection margin; EPE: extraprostatic extension; PV: prostate volume.

\section{Discussion}

PD placement after RP has previously been considered necessary (12). However, RP has changed significantly in recent years with the introduction of robot-assisted surgery. The reported incidence of post-RARP anastomotic leakage ranges between $0.1 \%$ and $6.7 \%(13-15)$ and the incidence of symptomatic lymphocele in patients undergoing RARP with extended pelvic lymph node dissection ranges between $1.2 \%$ and $5 \%(16-19)$. This study found similar anastomotic leak and symptomatic lymphocele rates $(4.5 \%$ and $0.3 \%$, respectively). In addition, the incidence of complications, such as ileus, UTI, anastomotic leakage and asymptomatic and symptomatic lymphocele did not differ according to PD placement, suggesting that routine PD placement is not necessary during RARP. Furthermore, the length of hospital stay was significantly shorter in the ND group.

We also found that lymph node dissection was the only significant independent predictor of postoperative asymptomatic lymphocele development. Previous reports have shown that lymphocele incidence increases after extended pelvic lymph node dissection and with the number of lymph nodes removed (20-23). Although PDs are placed to prevent lymphoceles, their absence did not predict asymptomatic lymphocele development two weeks after surgery in this study. A previous systematic review and meta-analysis reported that PD placement after RARP with extended pelvic lymph node dissection does not prevent symptomatic lymphocele or 
Table III. Analyses for prediction of asymptomatic lymphocele 2 weeks after surgery.

\begin{tabular}{|c|c|c|c|c|}
\hline & \multicolumn{2}{|c|}{ Univariable analysis } & \multicolumn{2}{|c|}{ Multivariable analysis } \\
\hline & $p$-Value & Odds ratio* & $p$-Value & Odds ratio* \\
\hline Age ( $\geq 70$ vs. $<70$ years $)$ & 0.83 & 0.94 & & \\
\hline BMI $\left(\geq 25\right.$ vs. $\left.<25 \mathrm{~kg} / \mathrm{m}^{2}\right)$ & 0.09 & 0.57 & 0.08 & 0.55 \\
\hline PSA $(\geq 10 v s .<10 \mathrm{ng} / \mathrm{ml})$ & 0.71 & 1.14 & & \\
\hline Prostate volume $(\geq 30 v s .<30 \mathrm{ml})$ & 0.52 & 0.81 & & \\
\hline Biopsy GS $(\geq 8 v s .<8)$ & 0.1 & 1.65 & 0.351 & 1.37 \\
\hline Clinical stage ( $\geq \mathrm{cT} 3 v s .<\mathrm{cT} 3)$ & 0.72 & 0.79 & & \\
\hline Neoadjuvant ADT (yes vs. no) & 0.41 & 0.73 & & \\
\hline \multicolumn{5}{|l|}{ D'Amico's risk classification } \\
\hline (high $v s$. low, intermediate) & 0.4 & 1.27 & & \\
\hline \multicolumn{5}{|l|}{ History of abdominal surgery } \\
\hline (yes vs. no) & 0.46 & 0.81 & & \\
\hline \multicolumn{5}{|l|}{ Operating time } \\
\hline$(\geq 240$ vs. $<240 \mathrm{~min})$ & 0.28 & 1.35 & & \\
\hline \multicolumn{5}{|l|}{ Console time } \\
\hline$(\geq 180 v s .<180 \mathrm{~min})$ & 0.37 & 1.28 & & \\
\hline Bleeding volume ( $\geq 150 \mathrm{vs} .<150 \mathrm{ml})$ & 0.08 & 1.63 & 0.054 & 1.75 \\
\hline Nerve sparing (yes $v s$. no) & 0.6 & 1.22 & & \\
\hline Lymph node dissection (yes vs. no) & 0.001 & 2.47 & 0.016 & 2.08 \\
\hline Pathological GS $(\geq 8 v s .<8)$ & 0.07 & 2.27 & & \\
\hline Pathological stage ( $\geq$ pT3 vs. $<$ pT3) & 0.34 & 1.38 & & \\
\hline Pelvic drain (yes vs. no) & 0.58 & 0.84 & & \\
\hline Drainage volume the day before drain removal $(\geq 100 \mathrm{vs} .<100 \mathrm{ml})$ & 0.9 & 1.05 & & \\
\hline
\end{tabular}

BMI: Body mass index; PSA: prostate specific antigen; ADT: androgen deprivation therapy; GS: Gleason score. *The odd ratio was described using the latter in parentheses as a reference.

postoperative complications (24), which also suggests that PD placement after RARP is not required. However, PD placement cannot be deemed unnecessary in all cases. PD placement may still be beneficial in patients undergoing extended pelvic lymph node dissection and those who are administered perioperative prophylactic low-molecular-weight heparin.

This study has several limitations. The sample size may have been too small to determine significant differences between groups. In addition, the proportion of patients who underwent lymph node dissection and median intraoperative blood loss significantly differed between the two study groups. Larger prospective studies and data from patients of other ethnic backgrounds are needed to confirm our findings. Future studies may indicate more clearly those patients who would benefit from PD placement.

PD placement after RARP did not affect the incidence of postoperative lymphocele development. Lack of a PD did not predict development of asymptomatic lymphocele two weeks after surgery. Future large-scale studies are required to identify patients that would benefit from PD placement.

\section{Conflicts of Interest}

All Authors declare that there are no potential conflicts of interest relevant to this article.

\section{Authors' Contributions}

H.I. and Y.K. designed the experiments. H.I., R.N., T.M., Y.K., H.Y., M.I., S.K. and T.K. collected clinical data. H.I., Y.K., T.K., K.S., K.I. and A.M. analyzed the data. H.I., Y.K. and A.M. drafted and revised the manuscript. All Authors read and approved the final version of the manuscript

\section{References}

1 Siegel RL, Miller KD and Jemal A: Cancer statistics, 2019. CA Cancer J Clin 69(1): 7-34, 2019. PMID: 30620402. DOI: 10.3322/caac. 21551

2 Iwamoto H, Izumi K, Shimada T, Kano H, Kadomoto S, Makino T, Naito R, Yaegashi H, Shigehara K, Kadono Y and Mizokami A: Androgen receptor signaling-targeted therapy and taxane chemotherapy induce visceral metastasis in castration-resistant prostate cancer. Prostate 81(1): 72-80, 2021. PMID: 33047850. DOI: $10.1002 /$ pros. 24082

3 Pepe $\mathrm{P}$ and Pennisi $\mathrm{M}$ : Prostate cancer diagnosis and management across twenty years of clinical practice: a singlecenter experience on 2,500 cases. Anticancer Res 39(3): 13971401, 2019. PMID: 30842174. DOI: 10.21873/anticanres.13254

4 Mottet N, Bellmunt J, Bolla M, Briers E, Cumberbatch MG, De Santis M, Fossati N, Gross T, Henry AM, Joniau S, Lam TB, Mason MD, Matveev VB, Moldovan PC, van den Bergh RCN, Van den Broeck T, van der Poel HG, van der Kwast TH, Rouvière 
O, Schoots IG, Wiegel T and Cornford P: EAU-ESTRO-SIOG Guidelines on prostate cancer. Part 1: Screening, diagnosis, and local treatment with curative intent. Eur Urol 71(4): 618-629, 2017. PMID: 27568654. DOI: 10.1016/j.eururo.2016.08.003

5 Basto M, Sathianathen N, Te Marvelde L, Ryan S, Goad J, Lawrentschuk N, Costello AJ, Moon DA, Heriot AG, Butler J and Murphy DG: Patterns-of-care and health economic analysis of robot-assisted radical prostatectomy in the Australian public health system. BJU Int 117(6): 930-939, 2016. PMID: 26350758. DOI: $10.1111 /$ bju.13317

6 Hu JC, Gu X, Lipsitz SR, Barry MJ, D'Amico AV, Weinberg AC and Keating NL: Comparative effectiveness of minimally invasive vs open radical prostatectomy. JAMA 302(14): 1557 1564, 2009. PMID: 19826025. DOI: 10.1001/jama.2009.1451

7 Hu JC, O'Malley P, Chughtai B, Isaacs A, Mao J, Wright JD, Hershman D and Sedrakyan A: Comparative effectiveness of cancer control and survival after robot-assisted versus open radical prostatectomy. J Urol 197(1): 115-121, 2017. PMID: 27720782. DOI: 10.1016/j.juro.2016.09.115

8 Yaxley JW, Coughlin GD, Chambers SK, Occhipinti S, Samaratunga H, Zajdlewicz L, Dunglison N, Carter R, Williams S, Payton DJ, Perry-Keene J, Lavin MF and Gardiner RA: Robot-assisted laparoscopic prostatectomy versus open radical retropubic prostatectomy: early outcomes from a randomised controlled phase 3 study. Lancet 388(10049): 1057-1066, 2016. PMID: 27474375. DOI: 10.1016/S0140-6736(16)30592-X

9 Antonelli A, Palumbo C, Noale M, Porreca A, Maggi S, Simeone C, Bassi P, Bertoni F, Bracarda S, Buglione M, Conti GN, Corvò R, Gacci M, Mirone V, Montironi R, Triggiani L, Tubaro A, Artibani W and Pros-IT CNR study group: Impact of surgical approach on patient-reported outcomes after radical prostatectomy: a propensity score-weighted analysis from a multicenter, prospective, observational study (The Pros-IT CNR Study). Urol Int 103(1): 8-18, 2019. PMID: 30731456. DOI: 10.1159/000496980

10 Nyberg M, Hugosson J, Wiklund P, Sjoberg D, Wilderäng U, Carlsson SV, Carlsson S, Stranne J, Steineck G, Haglind E, Bjartell $A$ and LAPPRO group: Functional and oncologic outcomes between open and robotic radical prostatectomy at 24-month follow-up in the Swedish LAPPRO trial. Eur Urol Oncol 1(5): 353-360, 2018. PMID: 31158073. DOI: 10.1016/j.euo.2018.04.012

11 Katayama H, Kurokawa Y, Nakamura K, Ito H, Kanemitsu Y, Masuda N, Tsubosa Y, Satoh T, Yokomizo A, Fukuda H and Sasako M: Extended Clavien-Dindo classification of surgical complications: Japan Clinical Oncology Group postoperative complications criteria. Surg Today 46(6): 668-685, 2016. PMID: 26289837. DOI: 10.1007/s00595-015-1236-x

12 Walsh PC: Anatomic radical prostatectomy: evolution of the surgical technique. J Urol 160(6 Pt 2): 2418-2424, 1998. PMID: 9817395. DOI: 10.1097/00005392-199812020-00010

13 Jacobsen A, Berg KD, Iversen P, Brasso K and Røder MA: Anastomotic complications after robot-assisted laparoscopic and open radical prostatectomy. Scand J Urol 50(4): 274-279, 2016. PMID: 26963663. DOI: 10.3109/21681805.2016.1145735

14 Novara G, Ficarra V, Rosen RC, Artibani W, Costello A, Eastham JA, Graefen M, Guazzoni G, Shariat SF, Stolzenburg JU, Van Poppel H, Zattoni F, Montorsi F, Mottrie A and Wilson TG: Systematic review and meta-analysis of perioperative outcomes and complications after robot-assisted radical prostatectomy. Eur Urol 62(3): 431-452, 2012. PMID: 22749853. DOI: 10.1016/ j.eururo.2012.05.044
15 Ou YC, Yang CK, Chang KS, Wang J, Hung SW, Tung MC, Tewari AK and Patel VR: Prevention and management of complications during robotic-assisted laparoscopic radical prostatectomy following comprehensive planning: a large series involving a single surgeon. Anticancer Res 36(4): 1991-1998, 2016. PMID: 27069192.

16 Agarwal PK, Sammon J, Bhandari A, Dabaja A, Diaz M, DusikFenton S, Satyanarayana R, Simone A, Trinh QD, Baize B and Menon M: Safety profile of robot-assisted radical prostatectomy: a standardized report of complications in 3317 patients. Eur Urol 59(5): 684-698, 2011. PMID: 21324583. DOI: 10.1016/j.eururo. 2011.01.045

17 Fischer B, Engel N, Fehr JL and John H: Complications of robotic assisted radical prostatectomy. World J Urol 26(6): 595602, 2008. PMID: 18584180. DOI: 10.1007/s00345-008-0287-7

18 DI Pierro GB, Grande P, Mordasini L, Danuser H and Mattei A: Safety and efficacy of robot-assisted radical prostatectomy in a low-volume center: A 6-year single-surgeon experience. Anticancer Res 36(8): 4201-4207, 2016. PMID: 27466532.

19 Keskin MS, Argun ÖB, Öbek C, Tufek I, Tuna MB, Mourmouris P, Erdoğan S and Kural AR: The incidence and sequela of lymphocele formation after robot-assisted extended pelvic lymph node dissection. BJU Int 118(1): 127-131, 2016. PMID: 26800257. DOI: 10.1111/bju.13425

20 Capitanio U, Pellucchi F, Gallina A, Briganti A, Suardi N, Salonia A, Abdollah F, Di Trapani E, Jeldres C, Cestari A, Karakiewicz PI and Montorsi F: How can we predict lymphorrhoea and clinically significant lymphocoeles after radical prostatectomy and pelvic lymphadenectomy? Clinical implications. BJU Int 107(7): 1095-1101, 2011. PMID: 20880192. DOI: 10.1111/j.1464-410X.2010.09580.x

21 Gotto GT, Yunis LH, Guillonneau B, Touijer K, Eastham JA, Scardino PT and Rabbani F: Predictors of symptomatic lymphocele after radical prostatectomy and bilateral pelvic lymph node dissection. Int J Urol 18(4): 291-296, 2011. PMID: 21306438. DOI: 10.1111/j.1442-2042.2010.02710.x

22 Musch M, Klevecka V, Roggenbuck U and Kroepfl D: Complications of pelvic lymphadenectomy in 1,380 patients undergoing radical retropubic prostatectomy between 1993 and 2006. J Urol 179(3): 923-8; discussion 928-9, 2008. PMID: 18207170. DOI: $10.1016 /$ j.juro.2007.10.072

23 Naselli A, Andreatta R, Introini C, Fontana V and Puppo P: Predictors of symptomatic lymphocele after lymph node excision and radical prostatectomy. Urology 75(3): 630-635, 2010. PMID: 19476977. DOI: 10.1016/j.urology.2009.03.011

24 Zhong W, Roberts MJ, Saad J, Thangasamy IA, Arianayagam R, Sathianathen NJ, Gendy R, Goolam A, Khadra M, Arianayagam M, Varol C, Ko R, Canagasingham B, Ferguson R and Winter M: A systematic review and meta-analysis of pelvic drain insertion after robot-assisted radical prostatectomy. J Endourol 34(4): 401408, 2020. PMID: 32037859. DOI: 10.1089/end.2019.0554
Received June 3, 2021

Revised June 16, 2021

Accepted June 17, 2021 